\section{Cerebral air embolism complicating esophagogastroduodenoscopy (EGD)}
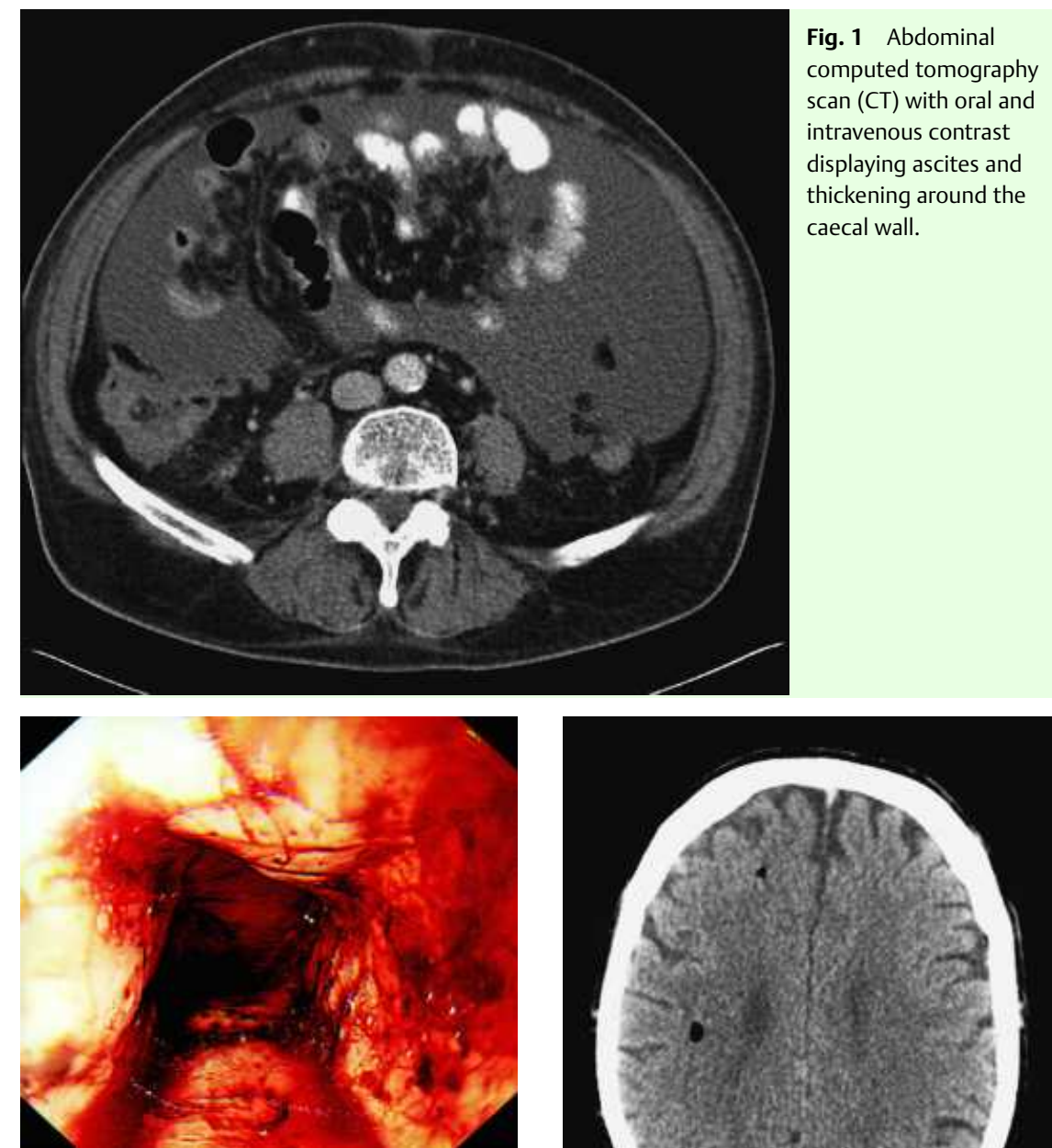

Fig. 2 Esophagogastroduodenoscopy (EGD) showed erosions and bleeding at the distal esophagus.

A 69-year-old man was admitted with progressive abdominal pain/distension, constipation, and vomiting. Abdominal computed tomography (CT) scan revealed ascites, omental deposits, and a thickened caecal wall ( Fig. 1). Ascitic fluid cytology confirmed adenocarcinoma. Hematemesis ensued and esophagogastroduodenoscopy (EGD) was performed to investigate this and the site of primary malignancy. This revealed distal erosive esophagitis ( $\bullet$ Fig. 2) from which biopsies were taken. Toward the end of the procedure the patient became unresponsive, exhibiting tonic-clonic seizure activity and a left hemiparesis. An emergency cerebral CT revealed pneumocephalus mostly affecting the right frontoparietal

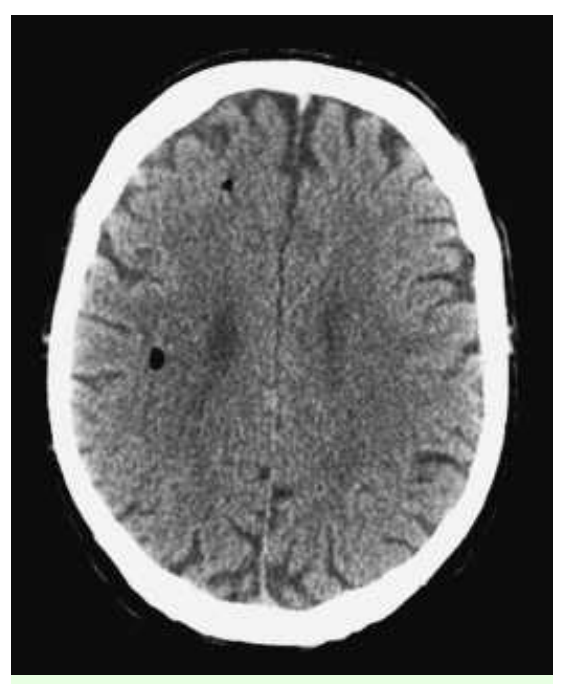

Fig. 3 CT scan of the brain performed with 1 hour after the cerebral event at EGD. Numerous small hypodensities consistent with air are displayed in the frontoparietal region of the right hemisphere

region ( Fig.3). Due to disseminated malignancy, transfer to the nearest operational hyperbaric oxygen unit $(>200$ miles) was felt to be unjustified. The patient died 6 days later. Postmortem examination within 24 hours showed no evidence of intracardiac air or shunt (॰ Fig.4). The underlying malignancy was appendiceal adenocarcinoma (๑ Fig. 5, 6).

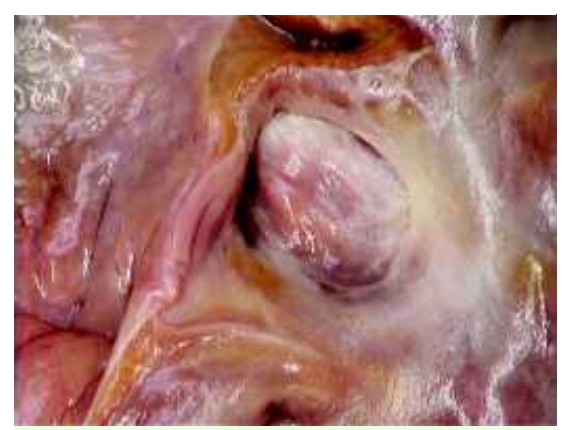

Fig. 4 Postmortem appearence of the intact atrial septum taken from the right side. The foramen ovale was found to be nonpatent.

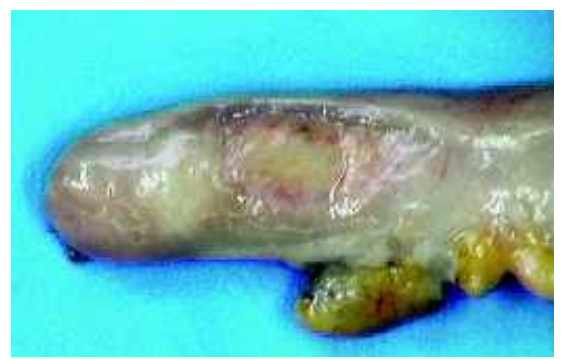

Fig. 5 Postmortem appearance of the appendiceal adenocarcinoma.

We identified eight previously reported cases of air embolism complicating EGD. One case involved intracardiac air and the other seven intracerebral. Invariably patients developed coma, seizures, and a dense left-sided hemiparesis, in keeping with EGD being performed in the left lateral position. Air enters the vascular system via disrupted mucosa in the setting of a pressure gradient due to insufflation [1]. Cerebral CT is highly sensitive for air embolism but diagnostic only if performed immediately, as air is rapidly reabsorbed from brain arterioles [2]. Paradoxical embolism may arise, even when an intracardiac shunt cannot be demonstrated [3]. Air may pass from the venous to the arterial system via prepulmonary arteriovenous shunts or by directly crossing the pulmonary capillary bed [4]. Treatment involves prevention of further embolization, high-flow oxygen, and hyperbaric oxygen therapy [5]. This case highlights a relatively unknown and very serious complication of an everyday hospital procedure. However, if signs are recognized early, prompt CT is diagnostic and hyperbaric oxygen therapy may improve the outcome.

Endoscopy_UCTN_Code_CPL_1AH_2AB 


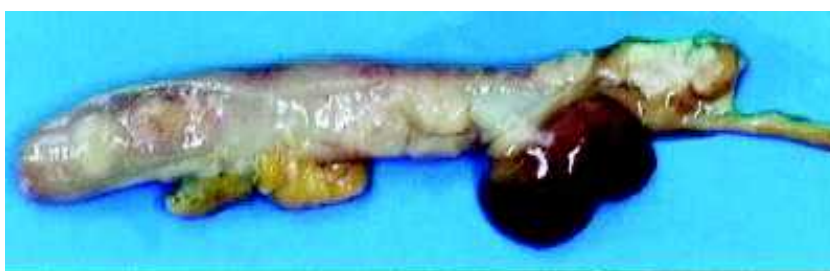

Fig. 6 Postmortem appearance of entire appendix with adenocarcinoma at the tip and an intraluminal caecal polyp.
Bibliography

DOI $10.1055 / \mathrm{s}-2007-995728$

Endoscopy 2008; 40: E191-E192

(c) Georg Thieme Verlag KG Stuttgart · New York . ISSN 0013-726X

\section{Corresponding author}

\section{B. J. McAree, MD}

28 Upper Malone Park

Belfast

BT9 6PP

Northern Ireland

Fax: +44-28-71611151

bjmcaree@doctors.org.uk

\section{B. J. McAree ${ }^{1}$, R. Gilliland ${ }^{1}$, D. M. Campbell' , J. W. Lucas², W. Dickey ${ }^{1}$}

1 Department of General Surgery, Department of Gastrointestinal Medicine, Altnagelvin Hospital, Londonderry, Northern Ireland

2 Department of State Pathologist, Foster Green Hospital, Belfast, Northern Ireland

\section{References}

1 Green BT, Tendler DA. Cerebral air embolism during upper endoscopy: case report and review. Gastrointest Endosc 2005; 61: 620-623

2 Wijman CA, Kase CS, Jacobs AK, Whitehead $R E$. Cerebral air embolism as a cause of stroke during cardiac catheterisation. Neurology 1998; 51: 318 - 319

3 Butler BD, Hills BA. Transpulmonary passage of venous air emboli. J Appl Physiology 1985; 59: 543-547

4 Thackray NM, Murphy PM, McLean RF, deLacy JL. Venous air embolism accompanied by echocardiographic evidence of transpulmonary air passage. Crit Care Med 1996; 24: $359-361$

5 Murphy BP, Harford FJ, Cramer FS. Cerebral air embolism resulting from invasive medical procedures. Treatment with hyperbaric oxygen. Ann Surg 1985; 201: $242-245$ 